OPEN ACCESS

ISSN 2579-5813 (online)

Edited by:

Nurdyansyah Nurdyansyah

Reviewed by:

Hartono Hartono,

Mu'alimin Mu'alimin

*Correspondence:

Agus Fathoni Prasetyo

Received: 5 Agustus 2020 Accepted: 9 September 2020 Published: 30 September 2020

Citation:

Prasetyo AF, Nurjanah $S$ and Mu'awanah Q (2020) The Effect of

Joyful Learning Strategies on Student Activeness in the Figh Learning Process in Class V MI. Madrosatuna: Journal of Islamic

Elementary School. 4:2. doi: 10.21070/madrosatuna.v4i2.94
The Effect of Joyful Learning Strategies on Student Activeness in the Fiqh Learning Process in Class V MI

\section{Pengaruh Strategi Joyful Learning Terhadap Keaktifan Siswa Pada Proses Pembelajaran Fiqih Di Kelas V MI}

\author{
Agus Fathoni Prasetyo*, Siti Nurjanah, Qoridatul Mu'awanah \\ Program Studi Pendidikan Guru Madrasah Ibtidaiyah, Fakultas Tarbiyah, Institut Agama Islam Nadhatul Ulama Tuban, \\ Indonesia
}

Education is an important capital for a person to live his life. The role of education is inseparable from the components of students, teachers, learning materials, learning media, learning models, and so forth. The main factors in the education described need to be improved because the progress of the civilization of a society or nation lies at the level of education. This research is also motivated by the low level of student activity during the learning process. The low student activeness is due to the way the teacher delivers the material and the educator rarely applies varied strategies in the learning process. So the learning process becomes monotonous and boring and causes students to assume that the figh lesson is not important and saturating, or they think it is enough to listen to the figh lesson as it is finished just like that, without any application. One strategy that can be used is to implement a joyful learning strategy or fun learning. This study aims to determine whether there is an influence of joyful learning strategies on student activity in the fiqh learning process especially in circumcision material at MI Miftahurrohman Senori Tuban. This type of pre-experimental research with the type of one group pretest-posttest design. The population in this study were class $V$ students consisting of one class that was used as an experimental class with a total of 14 students and all members of the population were sampled in this study. Data collection techniques were observation, tests (pretest and posttest) and documentation. The results of the study and discussion of the $t$ test calculations obtained that $t_{\text {hitung }}=2.197$ and $t_{\text {tabel }}=1.771$. This means that $\mathrm{t}_{\text {hitung }}$ is greater than $\mathrm{t}_{\text {tabel }}$ so it can be concluded that there is an influence of joyful learning strategies on student activeness in the learning process of figh in MI Miftahurrohman Senori Tuban class on circumcision material after being treated. Increased student activity is influenced by the use of learning strategies

Keywords: Joyful Learning Strategy, Student Activity, Fiqh

Pendidikan merupakan suatu modal penting bagi seorang untuk menjalani kehidupanya. Peran pendidikan tidak terlepas dari komponen-komponen peserta didik, guru, 
materi pembelajaran, media pembelajaran, model pembelajaran, dan lain sebagainya. Faktor utama dalam pendidikan yang dijelaskan tersebut perlu ditingkatkan kualitasnya sebab maju mundurnya peradaban masyarakat atau bangsa terletak pada tingkat pendidikan. Penelitian ini juga dilatar belakangi oleh rendahnya rataan keaktifan siswa pada saat proses pembelajaran. Keaktifan siswa yang rendah tersebut disebabkan karena cara penyampaian guru dalam memberikan materi dan pendidik jarang menerapkan strategi yang bervariasi dalam proses pembelajaran. Sehingga proses pembelajaran menjadi monoton dan membosankan serta mengakibatkan siswa menganggap bahwapelajaran fiqih itu tidak penting dan menjenuhkan, atau mereka beranggapan cukup dengan mendengarkan pelajaran fiqih itu selesai begitu saja, tanpa ada pengaplikasian. Salah satu strategi yang bisa digunakan adalah dengan menerapkan strategi joyful learning atau pembelajaran yang menyenangkan. Penelitian ini bertujuan untuk mengetahui apakah ada pengaruh strategi joyful learning terhadap keaktifan siswa pada proses pembelajaran fiqih khususnya pada materi khitan di MI Miftahurrohman Senori Tuban. Jenis penelitian pre-experimental dengan jenis one group pretest posttes. Populasi dalam penelitian ini adalah peserta didik kelas $\vee$ yang terdiri dari satu kelas yang dijadikan sebagai kelas eksperimen dengan jumlah 14 siswa dan semua anggota populasi tersebut dijadikan sampel dalam penelitian ini. Teknik pengumpulan data observasi, tes (pretest dan posttest) dan dokumentasi. Hasil penelitian dan pembahasan perhitungan uji t diperoleh bahwa $t_{\text {hitung }}=2,197$ dan $t_{\text {tabel }}=1,771$. Hal ini berarti bahwa $t_{\text {hitung }}$ lebih besar dari $t_{\text {tabel }}$ sehingga dapat disimpulkan bahwa terdapat pengaruh strategi joyful learning terhadap keaktifan siswa pada proses pembelajaran fiqih dikelas V MI Miftahurrohman Senori Tuban pada materi khitan setelah diberi perlakuan. peningkatan keaktifan siswa tersebut dipengaruhi oleh penggunaan strategi pembelajaran.

Kata Kunci: Strategi Joyful Learning, Keaktifan Siswa, Fiqh 


\section{PENDAHULUAN}

Pada hakikatnya Pendidikan adalah "usaha sadar memanusiakan manusia atau membudayakan" Sudjana (2010) . Manusia itu sendiri adalah pribadi yang utuh dan pribadi yang kompleks, sehingga sulit dipelajari secara tuntas. Oleh karena itu maslaha Pendidikan tak akan pernah selesai, sebab hakikat manusia itu sendiri selalu berkembang mengikuti dinamika kehidupan.

Mengingat Pendidikan selalu berkenaan dengan upaya pembinaan manusia, maka keberhasilan Pendidikan sangat bergantung kepada unsur manusianya, unsur yang paling menentukan keberhasilan Pendidikan adalah melaksanakan Pendidikan yaitu guru, gurulah ujung tombak Pendidikan, sebab guru secara langsung berupaya mempengaruhi, membina, dan mengembangkan kemampuan siswa, agar mejadi cerdas, trampil, dan bermoral tinggi. Dalam hal ini sesuai dengan tujuan Pendidikan di Indonesia yang tertuang dalam Undang-undang RI tahun 2003 sistem Pendidikan nasional pasal 3 yaitu:

"Pendidikan nasional berfungsi mengembangkan kemampuanan dan membentuk watak serta peradaban bangsa, yang bermartabat dalam rangka mencerdaskan kahidupan bangsa, bertujuan untuk berkembangnya potensi peserta didik agar menjadi manusia yang berimaan dan bertaqwa kepada Tuhan Yang Maha Esa, berakhlak mulia, sehat, cakap, kreatif dan menjadi warga negara yang demokrasi dan bertanggung jawab".

Adapun kesesuaian antara tujuan Pendidikan agama dengan tujuan pendidikan nasional di indonesia itu logisnya adalah betapa pentingnya Pendidikan agama, sehingga dapat diselenggarakan pada Pendidikan sekolah baik negeri maupun swasta, dimana Pendidikan tersebut dapat diberikan secara sistematis dan praktis dalam mencapai tujuan.

Persoalan yang sering dialami oleh sebagian besar orang adalah upaya belajar ternyata tidak membuat mereka mampu melakukan hal-hal yang mereka pelajari. Padahal, dalam konteks belajar, kondisi tersebut sesungguhnya tidak boleh terjadi. Setiap proses belajar seharunya mampu mengantarkan seorang pembelajar dari kondisi tidak memiliki menjadi memiliki, dari tidak bermakna menjadi bermakna yang selanjutnya memunngkinkan mereka untuk mengaktualisasikan diri mereka dalam hidup dan kehidupan. Sesuai UU Sisdiknas No. 20 Tahun 2003, belajar dimaknai sebagai bagian dari proses dari proses berkegiatan menciptakan sebuah pembangunan pencerahan.

Belajar seyogyanya menjadi sebuah langkah pembebasan yang dapat membuat seorang pembelajar terbebas dari segala kebingungan. Dari berbekal "kebebasan" yang telah mereka dapatkan tersebut, setahap demi setahap mereka akan mampu menjauh dari kebingungan dan melakukan hal yang berbeda dengan ketidakbingungan mereka. Dalam konteks tersebut, belajar dianggap sebagai sebuah manifestasi diri yang mendorong munculnya interaksi antara teori yang dipelajari dengan realitas sebagai subyek persoalannya Yamin (2015) .
Banyak strategi yang bisa dilakukan pada proses pembelajaran, namun dalam penelitian ini peneliti akan mencoba menguak strategi pembelajaran yang memiliki esensi menyenangkan tanpa sebuah tekanan. Proses ini akan sangat berpengaruh pada keaktifan siswa dan hasil pembelajaran. Menurut Sanjaya (2008) mengemukakan bahwa strategi pembelajaran adalah suatu kegiatan pembelajaran yang harus dikerjakan guru dan siswa agar tujuan pembelajaran dapat dicapai secara efektif dan efisien.

Sebagaimana yang terjadi dalam pembelajaran Fiqih Arifin et al. (2019) banyak praduga bahwa siswa mampu mengetahui pengertian khitan. Akan tetapi, banyak juga dari mereka yang belum mengetahui konsep-konsep dan sejarah dari khitan. Berdasarkan hasil pra penelitian yang dilakukan oleh peneliti dengan mewawancarai salah satu guru di MI Miftahurrohman Senori Tuban bahwa mata pelajaran fiqih tidak termasuk dalam materi pelajaran UAN, maka mengakibatkan siswa menganggap pelajaran fiqih itu tidak penting dan menjenuhkan atau mereka beranggapan cukup dengan mendengarkan pelajaran fiqih itu selesai begitu saja, tanpa ada pengaplikasian. Sehingga dalam proses pembelajaran Fiqih siswa kurang bisa aktif. akan tetapi apabila pembelajaran menggunakan strategi joyful l earning maka akan membuat siswa aktif dan kreatif.

Guru yang berhasil adalah guru yang bisa membuat siswa mampu memahami dan mempraktekkan materi yang disampaikan dengan strategi yang telah disiapkan. Guru dengan segala problematika hidupnya harus menjawab tantangan di era milenial dengan membuat pola pembelajaran yang kekinian. Oleh karena itu, guru harus tau bagaimana caranya membuat siswa itu senang mengikuti Pembelajaran Fiqih disekolahnya dan membuat siswa aktif dalam mengikuti pelajaran Fiqih. Salah satu cara adalah guru selalu menggunakan strategi dalam proses pembelajaran yang lebih menarik yakni salah satunya adalah dengan strategi Joyful learning.

Joyful Learning adalah sistem belajar yang menyenangkan pada proses pembelajaran. Mengingat pada kenyataan masa sekarang, sebagian besar siswa beranggapan bahwa belajar merupakan suatu hal yang sangat berat dirasakan. Hal itu disebabkan oleh proses pembelajaran yang sangat monoton dan membosankan atau kurang greget, sehingga tidak menimbulkan adanya sebuah tantangan. Hal ini tidak boleh dibiarkan terus menerus karena bisa mengaibatkan terbunuhnya daya kreatifitas para siswa secara perlahan. Kegiatan belajar yang menyenangkan dengan pola permainan bisa saja menjadi salah satu solusi alternatif untuk mengatasi kendala tersebut. Pembelajaran tidak selalu membutuhkan permainan, dan permainan sendiri tidak selalu dapat mempercepat pembelajaran, namun permainan yang dilaksanakan dengan tepat dapat menambah variasi, semangat dan minat pada sebagian program belajar Suyatna, dalam Nurjaman (2019) .

Joyful learning mempelajari sesuatu atau belajar dengan kondisi kegembiraan dan menyenangkan. Jika dilihat dari pelaksanaan pembelajaran yang ada di MI Miftahurrohman Senori tersebut, dalam menyampaikannya masih ada juga 
siswa yang belum mengikuti pelajaran dengan rasa senang serta kurangnya aktif di dalam kelas saat mengikuti proes pembelajaran Fiqih. Berdasarkan hasil pra penelitian, permasalahan yang dihadapi di MI Miftahurrohman Senori Tuban adalah guru masih menggunakan metode ceramah terlebih lagi pada pembelajaran fiqih dan kurangnya keaktifan siswa dalam mengikuti pelajaran

Penulis memilih melakukan penelitian di MI Miftahurrohman Senori Tuban karena di MI tersebut guru sering menggunakan metode ceramah dalam menyampaikan materi, dan guru di MI tersebut ingin mencoba merubah strategi mengajarnya menjadi lebih berkualitas, menyenangkan, mudah diingat, serta siswa mampu mengaplikasikan (mengamalkan ilmu yang diperolehnya) dalam kehidupan sehari-hari.

\section{METODE}

Penelitian ini merupakan penelitian kuantitatif dengan jenis penelitian eksperimen. Penelitian eksperimen merupakan metode penelitian yang digunakan untuk mencari pengaruh perlakuan tertentu terhadap yang lain dalam kondisi yang terkendalikan Sugiyono (2016). Penelitian ini dimaksudkan untuk meningkatkan keaktifan siswa yang berkaitan dengan proses pembelajaran di kelas. Khususnya dalam mengetahui keaktifan siswa pada materi pokok khitan dengan menggunakan strategi joyful learning.

Subjek dalam penelitian ini adalah siswa kelas V MI Miftahurrohman. Instrumen yang digunakan dalam penelitian ini adalah instrumen tes dan nontes. Instrumen tes berupa pretest dan posttest dengan 20 soal pilihan ganda, sedangkan instrumen nontes berupa lembar observasi dan dokumentasi.

\section{HASIL DANPEMBAHASAN}

Hasil peneitian kuantitatif ini diperoleh dari pelaksanaan pembelajaran dikelas pada materi pokok khitan dengan menggunakan strategi joyful learning yang dilakukan dikelas V MI Miftahurrohman Kecamatan Senori Kabupaten Tuban, yang berlangsung melalui 2 siklus pembelajaran dengan alokasi waktu $4 \times$ pertemuan atau $2 \times 35$ menit pada setiap pembelajaran. Pada pembelajaran pertama peniliti membagikan soal pretest sebelum memberikan perlakuan dan pada pembelajaran yang ke dua peneliti memberi perlakuan setelah itu baru membagikan soal posttest kepada siswa.

Berikut data hasil pretest dan posttest siswa kelas V MI Miftahurrohman tahun pelajaran 2019/2020.Tabel 1

Secara umum, siswa kelas V MI Miftahurrohman setelah diberi perlakuan mengalami peningkatan. Skor terendah siswa kelas $\mathrm{V}$ saat pretest adalah 50, setelah diberi perlakuan skor posttest terendah menjadi 55. Skor tertinggi pretest adalah 80 , setelah diberi perlakuan skor posttest tertinggi adalah 90 . Berdasarkan data hasil penelitian dapat diketahui bahwa nilai siswa mengalami peningkatan. Data tersebut dapat disajikan dalam bentuk grafik. Berikut grafik rekapitulasi data pretest dan posttest.

Dari Gambar 1 dapat dilihat skor sebelum diberi perlakuan dan skor setelah diberi perlakuan. dapat dilihat bahwa setelah diberi perlakuan dengan menggunakan strategi joyful learning terdapat 9 siswa yang mengalami peningkatan, 1 siswa yang yang tidak mengalami peningkatan maupun penurunan (seimbang), dan 4 siswa yang mengalami penurunan.

Berdasarkan Tabel 1 nilai pre test siswa dianalisis dan disajikan dalam sebuah tabel distribusi frekuensi dengan tujuan untuk memperjelas sebaran data, maka dapat disajikan dalam bentuk grafik. Grafik dibuat berdasarkan data frekuensi yang telah ditampilkan dalam bentuk tabel distribusi frekuensi. Berikut tabel distribusi frekuensi nilai pretest.Tabel 2

Berdasarkan Tabel 2 nilai pretest siswa kelas V MI Miftahurrohman pada pembelajaran fiqih, yang bertujuan untuk mengukur keaktifan siswa memperoleh nilai rata-rata 67,5 dengan standar deviasi 9.339 dibulatkan menjadi 9. Selanjutnya peneliti menyajikan data posttest dalam bentuk tabel distribusi frekuensi. Berikut tabel distribusi frekuensi nilai posttest.Tabel 3

Berdasarkan Tabel 3 nilai posttest siswa kelas V MI Miftahurrohman pada pembelajaran Fiqih dengan penerapan strategi joyful learning, yang bertujuan untuk mengukur keaktifan siswa memperoleh nilai rata-rata 72 dengan standar deviasi 9,511 dibulatkan menjadi 10. Dapat disimpulkan bahwa hasil pretest dan posttes ada peningkatan pada nilai rata-rata. Untuk nilai statistik disajikan pada tabel berikut:Tabel 4

Apabila hasil tes siswa dikelompokkan dalam kategori sangat aktif, aktif, cukup aktif, dan kurang aktif, maka akan diperoleh frekuensi dan persentase setelah dilakukan pretest dan posttest. Berdasarkan modifikasi Kemendikbud Kemendikbud (2013) kategori aktivitas siswa berdasarkan nilai menggunakan kategori: kurang aktif, cukup aktif, aktif, dan sangat aktif. Berikut tabel kategori keaktifan siswa berdasarkan nilai hasil pretest dan posttest.

Berdasarkan tabel 5 dapat diketahui bahwa pada pretest sebelum diberi perlakuan tidak ada siswa yang berada pada kategori sangat aktif, ada 7 siswa pada kategori aktif, 6 siswa pada kategori cukup, dan 1 siswa pada kategori kurang. Sedangkan pada posttest setelah diberi perlakuan terdapat 3 siswa dalam kategori sangat aktif, 6 siswa kategori aktif, 5 siswa kategori cukup, dan tidak ada siswa yang berada dalam kategori kurang. Selanjutnya peneliti menyajikan data pretest dan posttest dalam bentuk grafik. Berikut grafik perbandingan kategori keaktifan siswa pada mata pelajaran fiqih melalui pretest dan posttest.

Berdasarkan gambar 2 perbandingan kategori keaktifan siswa mengalami peningkatan pada posttest dalam kategori sangat aktif. Pada kategori sangat aktif mengalami penurunan pada pretest yaitu terdapat $0 \%$ siswa, dan posttest menjadi $21 \%$ siswa, kemudian untuk kategori aktif mengalami kenaikan pada pretest yaitu terdapat $50 \%$ siswa, sedangkan untuk posttest terdapat $43 \%$ siswa. Kemudian pada kategori cukup mengalami kenaikan pada nilai pretest yaitu terdapat $43 \%$ siswa, 
TABLE 1 | Data Hasil Pretest dan Posttest

\begin{tabular}{llll}
\hline No & Nama Siswa & Nilai & \\
& Pretest & Posttest \\
1 & A. Fiki Misbah & 80 & 80 \\
2 & Ah. Rizky Falihul & 75 & 70 \\
3 & Ahmad Rifan & 60 & 65 \\
4 & Dalla Jamila & 65 & 70 \\
5 & Hendri Setiawan & 50 & 55 \\
6 & Ismail Hasan & 70 & 65 \\
7 & Isna Amelia & 65 & 70 \\
8 & M. Hasby & 80 & 75 \\
9 & Moch Nawal Syifa & 65 & 60 \\
10 & Nur Tegar & 55 & 65 \\
11 & Rifqotul Aulia & 75 & 85 \\
12 & Rizal Afiqo & 60 & 70 \\
13 & Syafa Auliia & 75 & 90 \\
14 & Syifa Aurellia & 75 & 90 \\
\hline
\end{tabular}

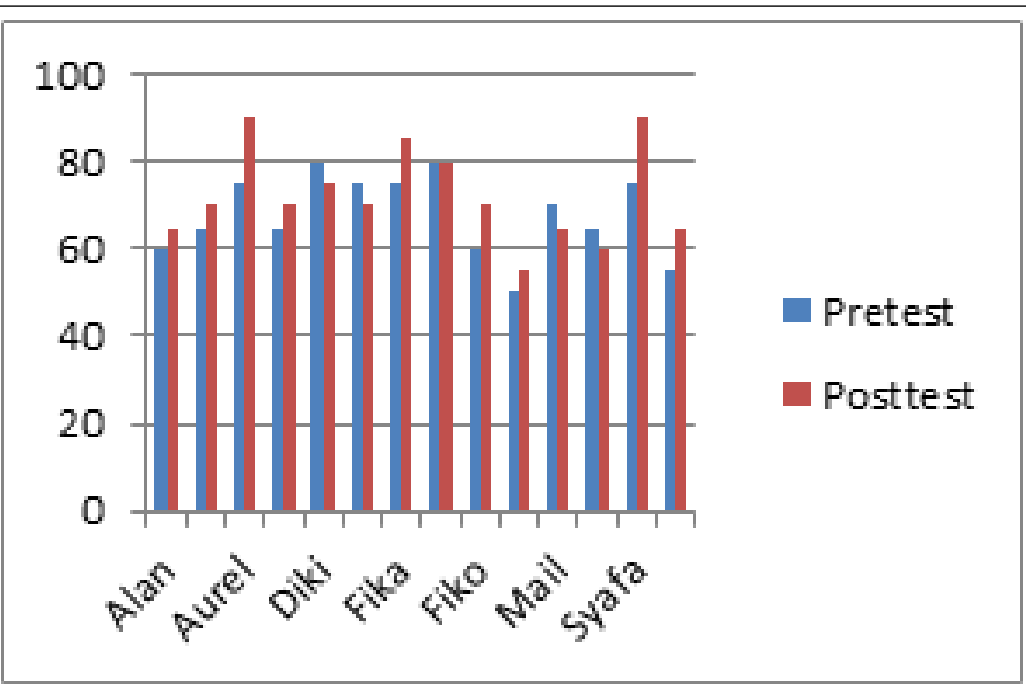

FIGURE 1 | Grafik Rekapitulasi Data Hasil Pretest dan Posttest

TABLE 2 | Distribusi Frekuensi Nilai Pretest

\begin{tabular}{lllllllll}
\hline Nilai & fi & xi & fi.xi & $\bar{x}$ & xi- $\bar{x}$ & $(x i-\bar{x})^{2}$ & fi (xi- $\bar{x})^{2}$ & $\%$ \\
$50-55$ & 2 & 52,5 & 105 & & -15 & 225 & 450 & 14,28571 \\
$56-61$ & 2 & 58,5 & 117 & & -9 & 81 & 162 & 14,28571 \\
$62-67$ & 3 & 64,5 & 193,5 & 67,5 & -3 & 9 & 27 & 21,42857 \\
$68-73$ & 1 & 70,5 & 70,5 & & 3 & 9 & 9 & 7,142857 \\
$74-80$ & 6 & 76,5 & 459 & & 9 & 81 & 486 & 42,85714 \\
$\sum$ & 14 & 322,5 & 945 & & -15 & 405 & 1134 & 100 \\
\hline
\end{tabular}

TABLE 3 | Distribusi Frekuensi Nilai Posttest

\begin{tabular}{|c|c|c|c|c|c|c|c|c|}
\hline Nilai & $\mathrm{fi}$ & $x i$ & fi.xi & $\bar{x}$ & $x i-\bar{x}$ & $(x i-\bar{x})^{2}$ & $f i(x i-\bar{x})^{2}$ & $\%$ \\
\hline $55-61$ & 2 & 58 & 116 & \multirow{6}{*}{72} & -14 & 196 & 392 & 14,28571 \\
\hline $62-68$ & 3 & 65 & 195 & & -7 & 49 & 147 & 21,42857 \\
\hline $69-75$ & 5 & 72 & 360 & & 0 & 0 & 0 & 35,71429 \\
\hline $76-82$ & 1 & 79 & 79 & & 7 & 49 & 49 & 7,142857 \\
\hline $83-90$ & 3 & 86 & 258 & & 14 & 196 & 588 & 21,42857 \\
\hline$\sum$ & 14 & 360 & 1008 & & 0 & 490 & 1176 & 100 \\
\hline
\end{tabular}


TABLE 4 | Data Statistik Nilai Pretest dan Posttest

\begin{tabular}{lll}
\hline \multirow{2}{*}{ Statistik } & \multicolumn{2}{l}{ Nilai Statistik } \\
& Pretest & Posttest \\
Nilai Tertinggi & 80 & 90 \\
Nilai Terendah & 50 & 55 \\
Nilai Rata-rata & 67,5 & 72 \\
Standar Deviasi & 9,339 & 9,511 \\
\hline
\end{tabular}

TABLE 5 | Tingkat Kategori Keaktifan Siswa

\begin{tabular}{llllll}
\hline Keaktifan & \multirow{2}{*}{ Kategori } & Pretest & & Posttest & \\
Siswa & & Frekuensi & Persentase & Frekuensi & persentase \\
$81-100$ & Sangat Aktif & 0 & $0 \%$ & 3 & $21 \%$ \\
$66-80$ & Aktif & 7 & $50 \%$ & 6 & $43 \%$ \\
$51-65$ & Cukup & 6 & $43 \%$ & 5 & $36 \%$ \\
$0-50$ & Kurang & 1 & $7 \%$ & 0 & $0 \%$ \\
& Jumlah & 14 & $100 \%$ & 14 & $100 \%$ \\
\hline
\end{tabular}

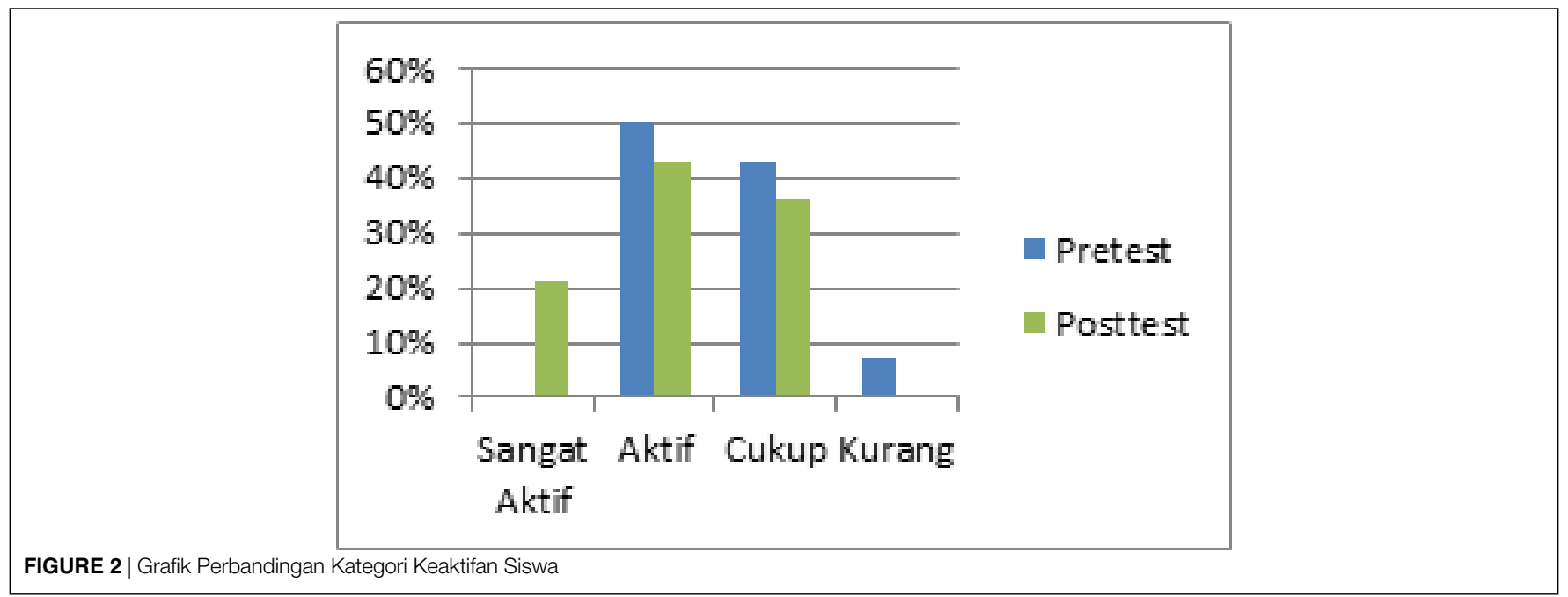

sedangkan untuk posttest terdapat $36 \%$ siswa. Pada pretest dengan kategori kurang terdapat $7 \%$ siswa dan $0 \%$ siswa untuk posttest.

Untuk mengkategorikan tingkat keaktifan siswa pada saat proses pembelajaran fiqih menggunakan strategi joyful learning, peneliti menggunakan rumus jumlah skor yang muncul dikalikan seratus kemudian dibagi dengan total skor maksimum. Berikut tabel kategori keaktifan siswa terhadap pembelajaran fiqih dengan menggunakan strategi joyful learning.

Berdasarkan tabel 6 diketahui bahwa terdapat 2 siswa yang kurang aktif dalam proses pembelajran, 2 siswa yang cukup aktif, 6 siswa yang aktif dan 4 siswa yang sangat aktif dalam proses pembelajaran fiqih denngan menggunakan strategi joyful learning. Kemudian peneliti menyajikan data tersebut dalam bentuk grafik. Berikut grafik persentase keaktifan siswa terhadap strategi joyful learning.

Berdasarkan gambar 3 terdapat 14\% siswa yang kurang aktif dalam proses pembelajaran fiqih dengan menggunakan strategi joyful learning, 14\% siswa yang cukup aktif, $43 \%$ siswa yang aktif, dan 29\% yang sangat aktif. Dapat disimpulkan bahwa penerapan strategi joyful learning dalam proses pem- belajaran fiqih dikelas V MI Miftahurrohman rata-rata dalam kategori aktif.

Adapun dalam pengujian hipotesis penelitian eksperimen peneliti menggunakan teknik statistik dengan menggunakan uji $\mathrm{t}$ jenis pretest and posttest one group design. Berikut tabel hasil analisis uji t one group pretest-posttest design:

Dari tabel 4.7 dapat diketahui $\left(\sum d\right)=60, \sum x_{d}=0.01$, dan $\sum x_{d}{ }^{2}=692,8572$ dengan jumlah siswa $\mathrm{N}=14$. Kemudian hasil perhitungan dibandingkan harga $\mathrm{t}_{\text {tabel }}$ dengan $\mathrm{df}=\mathrm{N}-1$ pada taraf signifikansi 0,05 sehingga diperoleh:

$\mathrm{t}_{\text {hitung }}=2,1974358974 / \mathrm{t}_{\text {hitung }}=2,197$

$\mathrm{t}_{\text {tabel }}=1,771$

$\mathrm{t}_{\text {hitung }}>\mathrm{t}_{\text {tabel }}=2,197>1,771$

Dari uraian diatas dapat diketahui bahwa dengan taraf signifikansi 0,05 $\mathrm{t}_{\text {hitung }}>\mathrm{t}_{\text {tabel }}$ dengan arti hipotesis nihil (Ho) ditolak, sedangkan hipotesis alternatif $(\mathrm{Ha})$ diterima. Jadi, ada pengaruh model pembelajaran joyful learning terhadap keaktifan siswa pada proses pembelajaran fiqih dikelas V MI Miftahurrohman Senori Tuban tahun pelajaran 2019/2020.

Penerapan strategi joyful learning pada pembelajaran fiqih materi pokok khitan dapat meningkatkan keaktifan siswa. Pen- 
TABLE 6 | Kategori Keaktifan siswa dalam Strategi JoyfulLearning

\begin{tabular}{llll}
\hline Skor Keaktifan Siswa & Frekuensi & Kategori & Presentase \\
$50-57$ & 2 & kurang & $14 \%$ \\
$58-65$ & 2 & cukup & $14 \%$ \\
$66-73$ & 6 & aktif & $43 \%$ \\
$74-83$ & 4 & sangat aktif & $29 \%$ \\
Jumlah & 14 & & $100 \%$ \\
\hline
\end{tabular}

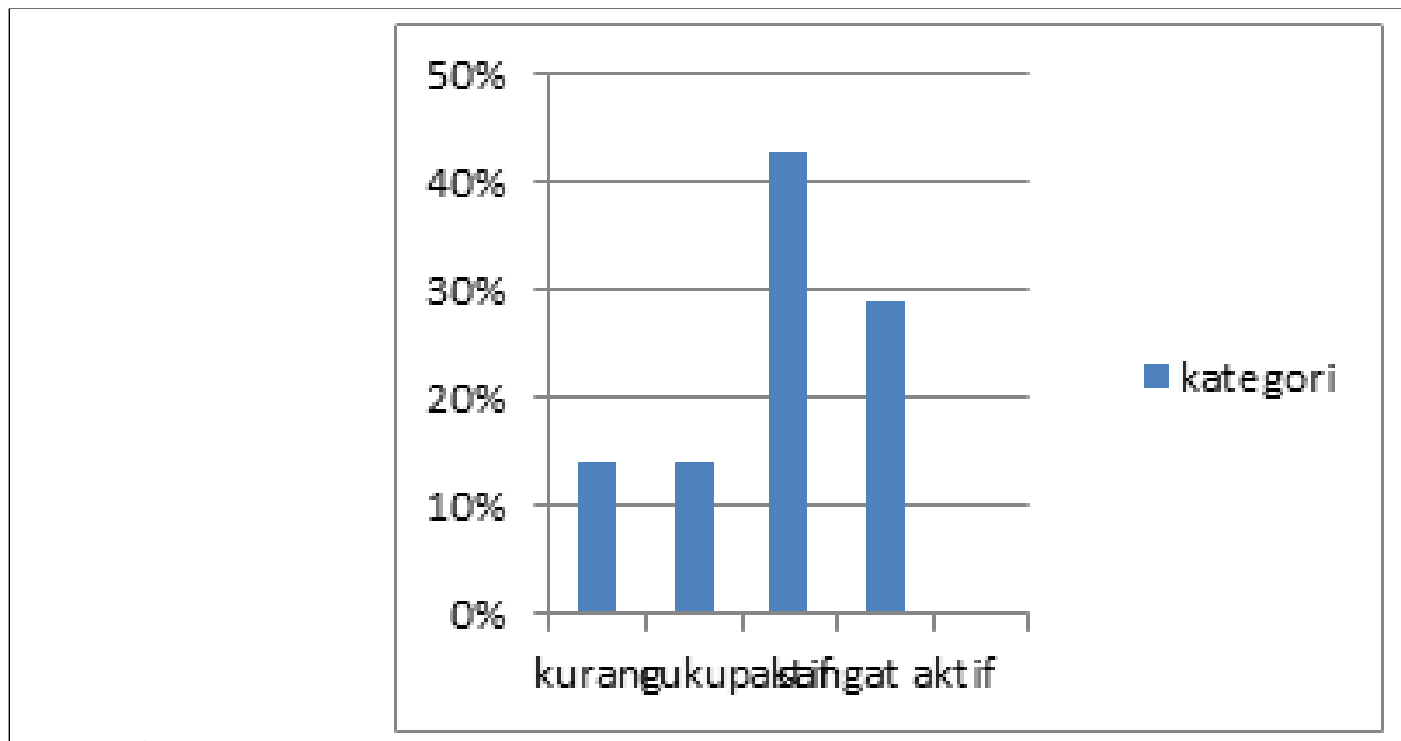

FIGURE 3 | Grafik Persentase Keaktifan Siswa terhadap Strategi Joyful Learning

TABLE 7 | Hasil Analisis

\begin{tabular}{llllll}
\hline No & Nama Siswa & Pretest & Posttest & $\begin{array}{l}x d \\
(d-m d)\end{array}$ & $x^{2}$ \\
1 & A. Fiki Misbah & 80 & 80 & $-4,29$ & 18,3612 \\
2 & Ah. Rizky & 75 & 70 & $-9,29$ & 86,2112 \\
3 & Ahmad Rifan & 60 & 65 & 0,72 & 0,5112 \\
4 & Dalla Jamila & 65 & 70 & 0,72 & 0,5112 \\
5 & Hendri Setiawan & 50 & 55 & 0,72 & 0,5112 \\
6 & Ismail Hasan & 70 & 65 & $-9,29$ & 86,2112 \\
7 & Isna Amelia & 65 & 70 & 0,72 & 0,5112 \\
8 & M. Hasby As- & 80 & 75 & $-9,29$ & 86,2112 \\
9 & Moch Nawal & 65 & 60 & $-9,29$ & 86,2112 \\
10 & Nur Tegar & 55 & 65 & 5,72 & 32,6612 \\
11 & Rifqotul Aulia & 75 & 85 & 5,72 & 32,6612 \\
12 & Rizal Afigo & 60 & 70 & 5,72 & 32,6612 \\
13 & Syafa Auliia & 75 & 90 & 10,72 & 114,8112 \\
14 & Syifa Aurellia & 75 & 90 & 10,72 & 114,8112 \\
Jumlah & 950 & 1010 & 0,01 & 692,8572 \\
\hline
\end{tabular}

ingkatan tersebut sebagai efek dari proses pembelajaran dengan menggunakan strategi joyful learning yang dirancang dengan baik. Peningkatan tersebut tampak dari hasil belajar yang dicapai oleh siswa melalui pretest dan posttest pada pembelajaran pertama dan kedua.

Berdasarkan analisis data observasi siswa, aspek dalam setiap sintaks telah banyak terlaksana. Hal ini menandakan bahwa kemampuan peneliti dalam mengelola kelas meningkat, yang akhirnya berdampak positif terhadap keaktifan siswa yang dapat ditunjukkan dengan meningkatnya nilai rata-rata dari hasil pretest ke posttest. peneliti sebagai mediator dan fasilitator juga sangat mengoptimalisasi perannya. Dapat diartikan bahwa pengaruh strategi joyful learning terhadap keaktifan siswa pada proses pembelajaran fiqih dikelas V MI Miftahurrohman Senori Tuban tahun pelajaran 2019/2020 berhasil. Hal ini sejalan bahwa keberhasilan belajar dapat ditentukan melalui faktor dari dalam dan luar individu bersangkutan, dari dalam adalah karena individu bersangkutan memiliki daya 
ingat, bakat dan keinginan untuk tidak berhenti berproses. Sementara dari luar adalah keberhasilan itu didukung oleh lingkungan yang sangat kondusif dan dinamis dalam dinamika pendidikan sehingga ini dapat memberikan warna baru bagi pembelajaran yang bermakna Yamin (2015) .

Strategi joyful learning ini efektif digunakan dalam pembelajaran fiqih karena mampu mengembangkan keakifan siswa dan memotivasi siswa serta meningkatkan keterlibatan siswa dalam proses kerja kelompok. Siswa terlihat lebih aktif dan bersemangat dalam proses pembelajaran.

Keberhasilan proses pembelajaran fiqih merupakan hasil dari ketepatan peneliti dalam memilih strategi dan media yang tepat dan efektif. Hal ini dapat mengurangi tingkat kejenuhan siswa dalam belajar, sehingga siswa tetap memiliki motivasi yang tinggi untuk belajar. Sesuai dengan teori bahwa pembelajaran menyenagkan berarti sesuai dengan pembelajaran yang tidak membosankan. Jika siswa terlibat langsung sebagai subjek belajar, mereka akan selalu senang dalam belajar Zuroidah (2005).

\section{KESIMPULAN}

Berdasarkan pembahasan hasil Penelitian kuantitatif yang telah dilakukan penulis, maka penulis menarik kesimpulan bahwa :

1. Bahwa pelaksanaan Strategi Joyful Learning di MI Miftahurrohman Senori Tuban dinilai aktif dan efektif. Hal ini terbukti dari tahapaan dalam penggunaan strategi Joyful

\section{REFERENCES}

Arifin, M. B. U. B., Nurdyansyah, Rindaningsih, I., and Fauji, I. (2019). Universal Journal of Educational Research 7, 1820-1825. doi: 10.13189/ujer.2019.070821.

Kemendikbud (2013). Kementrian Pendidikan dan Kebudayaan tahun 2013 tentang kriteria Hasil Belajar.

Nurjaman, A. (2019). Joyful Learning (Bogor: Guepedia Publisher).

Sanjaya, W. (2008). Strategi Pembelajaran Berorientasi Standar Proses Pendidikan (Jakarta: Prenada Media Grouf)

Sudjana, N. (2010). Cara Belajar Siswa Aktif (Bandung: Sinar Baru Algensindo).

Sugiyono (2016). Metode Penelitian Kuantitatif Kualitatif, dan R\&D (Bandung: Alfabeta).

Yamin, M. (2015). Teori Dan Metode Pembelajaran (Malang: Madani (Kelompok Intrans Publishing) Wisma Kalimetro).
Learning yaitu: guru mempunyai kesiapan pembuka, pelaksanaan penyampaian pembelajaran dengan menggunakan media, strategi, presentasi yang baik, guru juga mempunyai latihan, penguat serta penutup.

2. Bahwa keaktifan siswa kelas V di MI Miftahurrohman tergolong sebagai siswa aktif. Hal ini terbuktikan dari hasil penelitian dengan menggunakan lembar observasi yang menunjukkan prosentase sebesar $43 \%$, yang dapat dibuktikan dengan skor keaktifan siswa dari 66-73 yang tergolong aktif. Dan dengan ketentuan siswa aktif mengajukan suatu pertanyaan, mendengarkan penyajian materi yang diberikan gu

3. Strategi Joyful Learning di MI Miftahurrohman Senori Tuban mempunyai pengaruh yang signifikan terhadap keaktifan siswa.

Berdasarkan kesimpulan dari hasil penelitian di atas, maka peneliti memberikan saran kepada pendidik agar dapat menerapkan strategi joyful learning dikelas. Penerapan ini untuk meningkatkan keaktifan siswa dalam proses pembelajaran. Beberapa cara dapat diterapkan pendidik seperti tahapan persiapan, penyampaian, pelatihan dan penutupan. Pendidik diharapkan mampu menciptakan lingkungan belajar yang rileks, hangat, mendorong kepercayaan diri peserta didik dan memanusiakan peserta didik. Kepada seluruh peserta didik hendaknya lebih memahami arti dan manfaat dari pembelajaran fiqih agar tetap merasa senang dan lebih meningkatkan keaktifannya dan kreatifitasnya di dalam mengikuti pelajaran fiqih.
Conflict of Interest Statement: The authors declare that the research was conducted in the absence of any commercial or financial relationships that could be construed as a potential conflict of interest.

Copyright (0) 2020 Prasetyo, Nurjanah and Mu'awanah. This is an open-access article distributed under the terms of the Creative Commons Attribution License (CC BY). The use, distribution or reproduction in other forums is permitted, provided the original author(s) and the copyright owner(s) are credited and that the original publication in this journal is cited, in accordance with accepted academic practice. No use, distribution or reproduction is permitted which does not comply with these terms. 